\title{
Planejamento Ambiental, Turismo e Sustentabilidade: o potencial natural da Lagoa do Bacuri, Maranhão-Brasil.
}

\author{
Environmental Planning, Tourism and Sustainability: the natural potential of Lagoa do \\ Bacuri, Maranhao, Brazil. \\ Ribeiro $^{1}$, N. dos R.; Rabelo ${ }^{1}$, T. O.; Santos ${ }^{1}$, N. M.; \\ naiara20ribeiro@hotmail.com;.
}

\begin{abstract}
Resumo
As atividades turísticas ocorrem em porções significativas da superfície terrestre que influenciam e modificam o espaço geográfico. O Maranhão possui um potencial ecoturístico diversificado que abrange desde ambientes como a baixada maranhense até o Delta do Parnaíba. Neste contexto destacamos a Lagoa do Bacuri que possui grande potencial paisagístico, que desperta atração de uma quantidade de visitantes de várias cidades, principalmente da região do Baixo Parnaíba. O ambiente é dotado de belezas naturais, ligadas principalmente ao seu potencial hídrico, vegetal e geomorfológico. Com esta pesquisa busca-se evidenciar as potencialidades naturais para o desenvolvimento do turismo sustentável na Lagoa do Bacuri a partir da análise do potencial natural e dos processos que atuam no ambiente. A pesquisa teve como principais procedimentos metodológicos a pesquisas bibliográficas e cartográficas referentes à área de estudo, e utilização de técnicas de sensoriamento remoto e geoprocessamento para identificação das áreas e jornadas de campo. A lagoa do Bacuri possui potencial natural para desenvolver segmentos do turismo ecoturismo, turismo rural, turismo de aventura e etc. Porém é necessário que haja um interesse mútuo por parte do poder público, das populações da região e da iniciativa privada para o desenvolvimento do turismo local.
\end{abstract}

Palavras-chave: Turismo, Potencialidade, Lagoa do Bacuri

\begin{abstract}
The tourist activities occur in significant portions of the earth's surface that influence and modify the geographical space. Maranhão has a diverse eco-tourism potential that ranges from environments such as Maranhão lowered to the Delta of. In this context we emphasize the Bacuri pond that has great landscape, awakening attracting a number of visitors from various cities, mainly in the Lower Parnaíba region. The environment is endowed with natural beauty, mainly linked to its water potential, plant and geomorphological. This research seeks to highlight the natural potential for the development of sustainable tourism in Lagoa do Bacuri from the natural potential analysis and processes that act on the environment. The research had as main methodological procedures to bibliographic and cartographic research related to the study area, and use of remote sensing and geoprocessing to identify areas and field days. The pond of Bacuri has natural potential to develop ecotourism segments, rural tourism, adventure tourism, etc. But there needs to be a mutual interest by the government, the people of the region and the private sector for the development of local tourism.
\end{abstract}

Keywords: Tourism, Potentiality, Lagoa do Bacuri

\section{INTRODUÇÃO}

Sabe-se que as novas formas de organização humana e a intensificação das formas de exploração da natureza estão causando intervenções que nem sempre são saudáveis para a natureza. Como forma de garantia para a continuidade da espécie humana é essencial que haja o controle dos desequilíbrios ambientais causados pela intensa atuação do homem no ambiente.

A diversidade de atributos naturais no ambiente influenciou o homem à escolha de áreas providas de quantidade maiores de recursos naturais utilizados para sua sobrevivência e desenvolvimento, a partir de ações diferenciadas. Relacionadas ao ambiente, as ações sustentáveis e 
o desenvolvimento econômico, desde que haja interesse da coletividade, podem ser relacionados em diversas atividades humanas.

Dentre as formas de atuação humana no ambiente, destacamos as atividades turísticas, que ocorrem em porções significativas da superfície terrestre e que influenciam e modificam o espaço geográfico. As atividades turísticas geram deslocamentos humanos, transformam e criam espaços diferenciados, baseando-se em ações que utilizam e modificam os recursos naturais.

Segundo a OMT (2003), essa atividade deve levar em conta um modelo de desenvolvimento econômico que permita: melhorar a qualidade de vida das comunidades anfitriãs; promover uma qualidade elevada na experiência do visitante e manter a qualidade do ambiente, assegurando a distribuição equitativa dos benefícios e dos custos; a compreensão dos impactos do turismo no ambiente cultural, humano e material; melhorar as infraestruturas sociais e de cuidados de saúde.

O levantamento do potencial turístico compreende o inventário e diagnóstico do local ou zona turística, enfatizando-se os monumentos naturais, os recursos hídricos, o comportamento do clima, o patrimônio cultural e as manifestações folclóricas de um determinado local (SEABRA, 2007).

O Maranhão possui um potencial ecoturístico diversificado e exótico que abrange desde ambientes como a baixada maranhense, mata dos cocais, o sertão maranhense até o Delta do Parnaíba, e é neste contexto que destacamos a Lagoa do Bacuri, situada próximo a região maranhense do Delta do Parnaíba, localizada nos munícipios de São Bernardo e Magalhães de Almeida.

A Lagoa do Bacuri possui grande potencial paisagístico, que desperta atração de uma quantidade de visitantes de várias cidades, principalmente da região do Baixo Parnaíba. O ambiente é dotado de belezas naturais, ligadas principalmente ao seu potencial hídrico, vegetal e geomorfológico. Porém, o turismo nesta área acontece de forma incipiente, tendo uma atenção mínima da população local e nenhum apoio por parte do poder público.

Esta pesquisa tem como objetivo analisar as potencialidades naturais da Lagoa do Bacuri MA para o desenvolvimento do turismo sustentável na sua área de abrangência a partir da verificação dos seus atributos biodiversos e dos processos e interações que atuam no ambiente. Sendo, a partir daí possível pensar em propostas que auxiliem no planejamento e gestão da área levando-se em consideração a conservação dos elementos naturais que influenciam direta ou indiretamente a área de estudo. 


\section{METODOLOGIA}

A Teoria Geossistêmica foi utilizada para dar a poio a esta pesquisa, onde Sotchava (1977) chama a atenção para o fato de que os geossistemas, embora sejam considerados "fenômenos naturais", devem ser estudados à luz dos fatores econômicos e sociais que influenciam sua estrutura. Os geossistemas podem refletir parâmetros sociais e econômicos que influenciam importantes conexões em seu interior. Um geossistema não se subdivide ilimitadamente: as unidades espaciais acham-se na dependência da organização geográfica; fato de fundamental importância para análise da pesquisa.

Segundo Monteiro (2001), a aplicação do método geossistêmico auxilia nas estruturas dos chamados subsistemas, através de uma hierarquia da dinâmica espacial e ambiental e também natural e social, que apresentam caráter vertical e horizontal, desempenhando a análise geográfica de forma estruturada e hierárquica.

Para alcance dos objetivos propostos nesta pesquisa, foram necessários os seguintes procedimentos metodológicos:

- Levantamento e análise de material bibliográfico de documentos oficiais Zoneamento Ecológico Econômico do Baixo Parnaíba (2002) e autores como Aranha e Guerra, 2014 e estudos de casos em diferentes áreas que envolvem a prática de ações que auxiliem no desenvolvimento do turismo a partir da conservação ambiental, assim como destacando uma gestão integrada entre o poder público e a sociedade civil, como as pesquisas de Santos, Neto, Souza e Feitosa (2014); Rabelo (2015); Santos (2015), Ribeiro (2015) e Feitosa (2015), o que auxiliaram a discussão sobre o assunto;

- Levantamento de Material cartográfico, a nível de conhecimento da delimitação da área maranhense da Lagoa do Bacuri e a localização das comunidades situadas no seu entorno, com vistas na identificação de sua situação geográfica e caracterização paisagística;

- Compatibilização das escalas dos mapas, cartas DSG e imagens de satélite disponibilizadas pelo INPE e pelo Google Earth da área de estudo para a escala de trabalho em 1:50.000, para a região e 1:25.000 ou maior para conhecimento da povoação populacional da área estudada e sua evolução visando compreender a influência deste aspecto no desenvolvimento do turismo na área;

- Jornadas de campo para observação do potencial natural da área, fluxo turístico, participação da comunidade nas atividades relacionadas ao turismo da área e a atuação do poder público em relação à atividade turística a fim de perceber as implicações mais visíveis na área de estudo; 
-Análise, interpretação e representação dos dados das fontes primárias, obtidos através das atividades de campo, e secundárias, relativas à área estudada e à temática abordada que subsidiaram as discussões realizadas na pesquisa.

\section{RESULTADOS E DISCUSSÃO}

\subsection{Localização e Situação Geográfica}

Localizada na porção nordeste do Estado do Maranhão, a Lagoa do Bacuri é considerada o maior corpo hídrico lagunar marginal ao Rio Parnaíba, nesta região. Abrange os municípios de São Bernardo e Magalhães de Almeida (Figura 01) e segundo Almeida Jr. (2012) possui um perímetro $63,52 \mathrm{~km}$, a lagoa ocupa uma área de $26,46 \mathrm{~km}^{2}$, tendo $23,75 \mathrm{~km}$ de comprimento e medindo 2,48 $\mathrm{km}$ no ponto de maior largura.

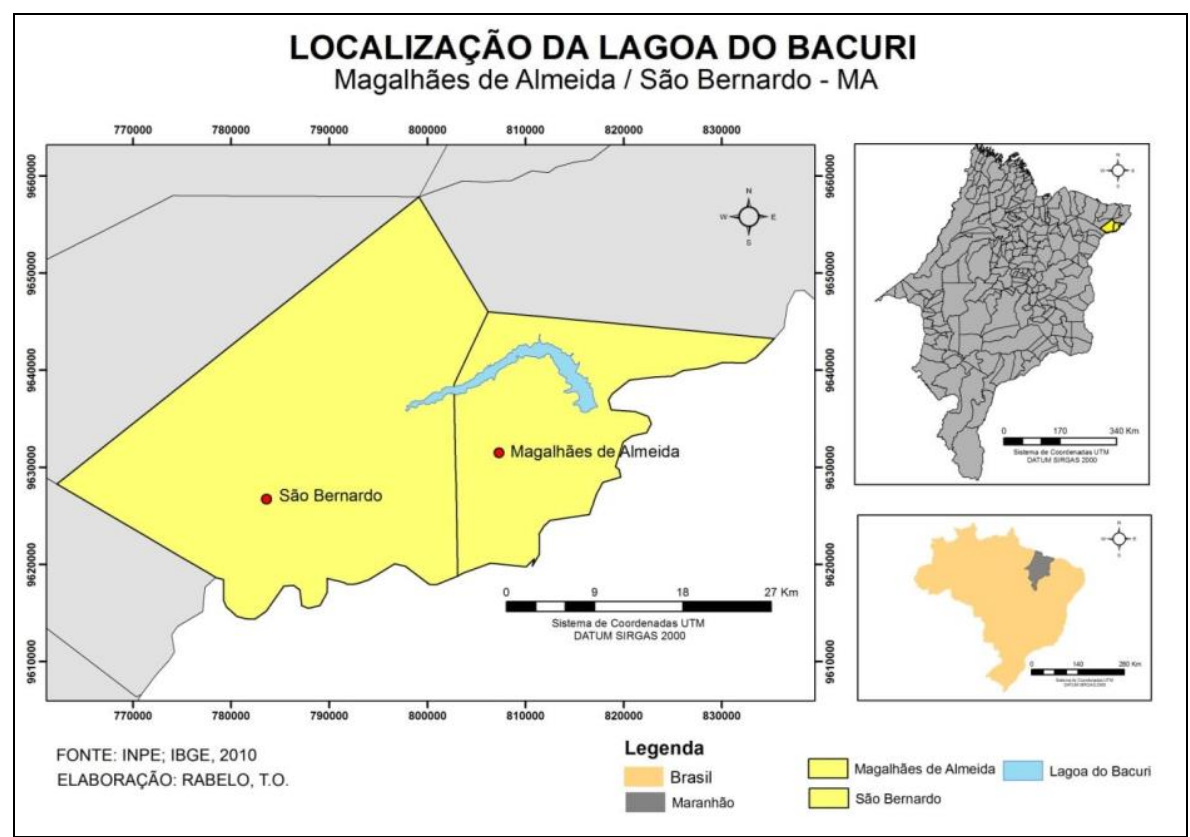

Figura 01: Localização da Lagoa do Bacuri. Fonte: Rabelo, 2015.

A lagoa do Bacuri (Figura 02) dá suporte para o sustento de um diverso ecossistema que é a base fundamental para a alimentação, ocupação e geração de renda e fonte de lazer de cerca de 31 comunidades em seu entorno. A relação das comunidades com o ambiente em questão causa impactos pontuais ao ambiente, relacionados principalmente a poluição e retirada de cobertura vegetal. 


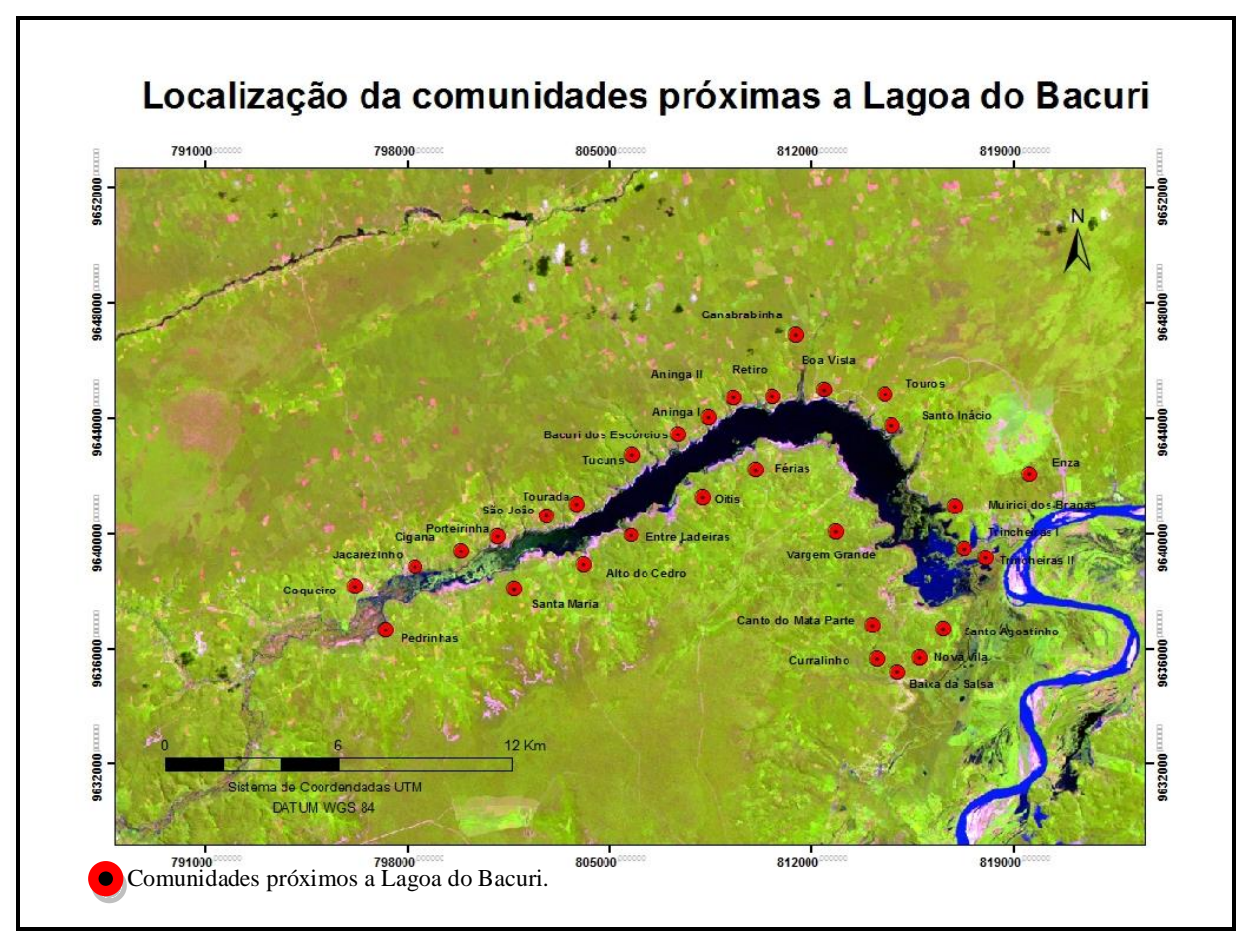

Figura 02: Localização das comunidades próximas a Lagoa do Bacuri. Fonte: Rabelo, 2015.

\subsection{Potencialidades Naturais para o desenvolvimento do Turismo}

A Lagoa do Bacuri possui potencial paisagístico exuberante, sendo um fator de grande relevância para o desenvolvimento de atividades turísticas. Pelo fato de ainda ser pouco conhecida, a Lagoa do Bacuri possui uma beleza paisagística pouco evidenciada, fator que geralmente é dado como destaque a todos que visitam a área.

Uma área ainda pouco conhecida pelas pessoas do Estado do Maranhão, é bastante frequentada por visitantes de Parnaíba - PI, do Ceará e alguns municípios próximos da Lagoa; poucas são as pessoas de São Luís que a conhecem, com exceção dos que possuem familiares na região. Estes visitantes são atraídos principalmente pela beleza que o potencial hídrico e vegetacional proporcionam a região.

Para o turismo, a paisagem é vista como um atrativo que é eminentemente observado, vivido e sentido (Boas e Marçal, 2014). Sendo assim, Xavier (2007) afirma que a atividade turística desempenha papel relevante, uma vez que a paisagem agrega, em sua conceituação, valores ao que é percebido e sentido, remetendo o termo paisagem como atrativo que deve ser valorizado e conservado. 


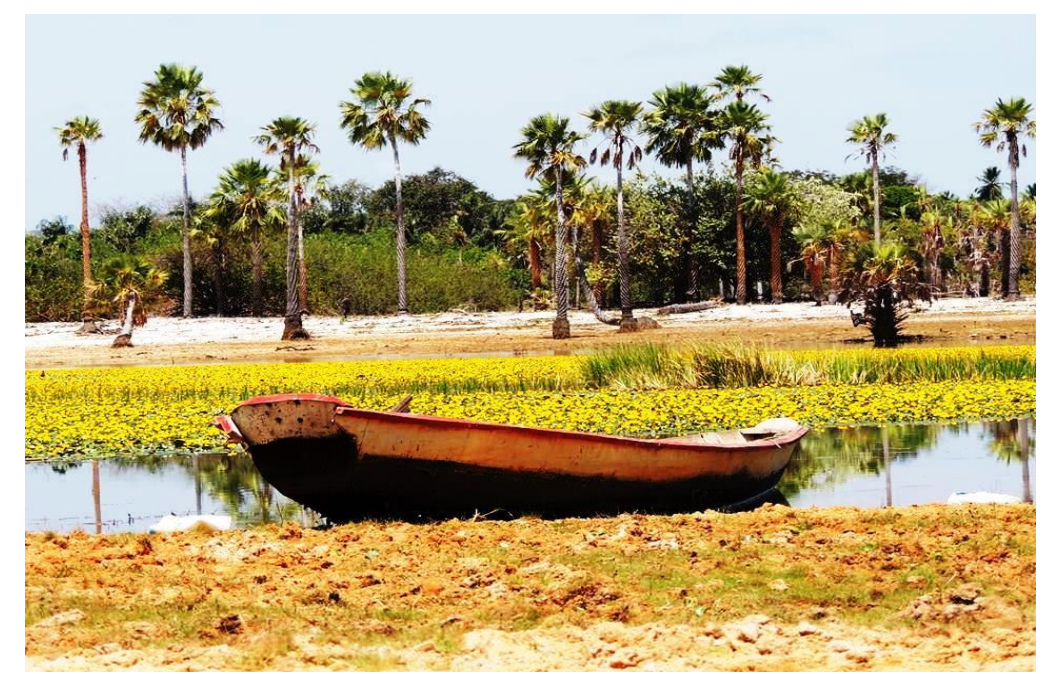

Figura 03: Lagoa do Bacuri - Magalhães de Almeida. Fonte: Registro da Pesquisa, 2015.

Há bastante possibilidades para que seja realizado na área a prática do ecoturismo, do turismo de aventura e do turismo rural, pois a área ainda encontra - se bastante preservada, visto que as características naturais da área, relacionadas principalmente aos recursos hídricos, geomorfologia e a vegetação, potencializam estas atividades

No entanto, os turistas que frequentam a lagoa percebem a ausência de uma outra atividade para descontração, além do tradicional banho. Neste sentido, as atividades que poderiam ser desenvolvidas na área são a prática de caiaque, stand up peaddle, trilhas, ralis, entre outros atividades que utilizassem de forma sustentável o potencial natural da área.

Entretanto, a lagoa do Bacuri não possui uma infraestrutura adequada para a recepção dos visitantes no que diz respeito a acomodações para pernoite e também para alimentação. Existe apenas um bar próximo a sua margem, mas não é aberto regularmente, contendo apenas a venda de bebidas. Como consequência, os frequentadores levam refeições prontas para o consumo no local. Além disso, na comunidade não há pessoas capacitadas para o atendimento de forma correta desses turistas (RIBEIRO, 2015).

O investimento por parte do poder público nesta área é inexistente, pois a atividade turística não é vista como prática importante por parte dos seus gestores e consequentemente não traz retorno econômico às comunidades da área, visto que desconhecem o potencial que possuem para a prática do ecoturismo, por exemplo

É neste contexto que se destaca a importância de ações relacionadas a instrumentalização da comunidade para que possam aderir a essa atividade de forma adequada, utilizando de ações e planejamentos próprios para a realidade em que vivem. De forma que consigam utilizar da sustentabilidade como aliada para a geração de renda para a comunidade e tendo assim, um ambiente saudável com condições para proporcionar essa troca. 
Além da prática do turismo, a lagoa do Bacuri dá suporte para o sustento de um diversificado ecossistema que é a base fundamental para a alimentação, ocupação, geração de renda e fonte de lazer das comunidades em seu entorno e até de outras localidades (MARQUES, 2014), pois é da lagoa que eles retiram o peixe do qual se alimentam, além disso, também utilizam dela para atividades seculares.

É importante destacar que alguns povoados desta área receberam iniciativas relacionadas ao desenvolvimento de um turismo comunitário pautado na sustentabilidade e que buscaram enfatizar o potencial turístico natural da área, como é o caso do projeto Turismo Sustentável na comunidade do Bacuri: Inclusão Social na Conservação da Lagoa do Bacuri, Município de Magalhães de Almeida, Estado do Maranhão.

Este projeto foi desenvolvido pelo Núcleo de Estudos e Pesquisas Ambientais (NEPA) do curso de Geografia da Universidade Federal do Maranhão e contou com o apoio de professores e estudantes do curso de geografia em parceria com pesquisadores do curso de Turismo da instituição, que desenvolveram atividades de sensibilização e capacitação com algumas comunidades, voltadas para as temáticas turismo, sustentabilidade e ambiente. Porém, estas iniciativas ainda são poucas na região, sendo de suma importância ações e projetos nessa perspectiva

\subsection{Alterações ambientais e o desenvolvimento do turismo na Lagoa do Bacuri - MA}

A utilização dos recursos naturais pelas comunidades do entorno da Lagoa do Bacuri acontece de forma intensa. A maioria das atividades socioeconômicas praticadas pela população estão baseadas na agricultura familiar, pesca, extrativismo vegetal e animal. Estas práticas tradicionais ocasionam uma série de problemas ambientais que comprometem a sustentabilidade do ambiente, como o acúmulo de resíduo sólido, desmatamento, queimadas, assim como lançamento de restos de produtos químicos relacionados a lavagem de roupa e veículos nas margens da lagoa.

Além destas atividades, intensificou-se na região, nas últimas décadas, a agricultura mecanizada, caracterizada pelo cultivo da soja, causando alterações significativas na dinâmica ambiental da Lagoa do Bacuri. Rabelo e Feitosa (2014) destacam que as principais alterações presentes na área se refere ao aumento das áreas de cultivo, na porção do município de São Bernardo; este ponto é um dos que mais vêm sofrendo impactos visto que nesta área são lançadas quantidades expressivas de resíduos sólidos, assim como a cobertura vegetal dessa parte de suas margens encontram-se intensamente reduzidas.

Estudos realizados por Rabelo (2015) afirmam que embora, os impactos ambientais causados pela ação humana ainda não tenham alterado de forma efetiva a capacidade resiliência do ecossistema no qual está inserida a Lagoa do Bacuri é possível observar as alterações que estão 
ocorrendo neste ambiente, evidente nos últimos vinte anos, causaram alterações progressivas na paisagem da local, aumentando principalmente as áreas de cultivo e aumentando as áreas de vegetação arbustiva e solo exposto (Figuras 04 e 05).

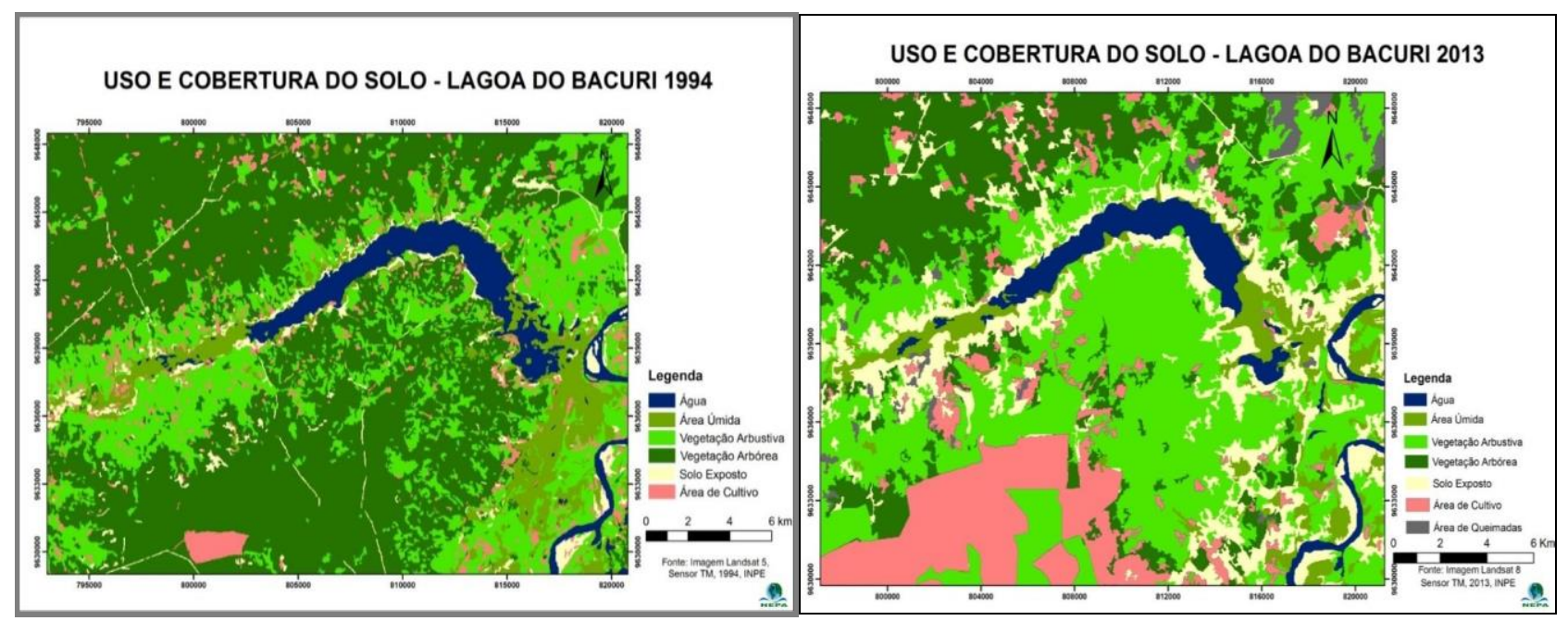

Figura 04 e 05: Uso e cobertura da terra - Lagoa do Bacuri, 1994 e 2013. Fonte: Rabelo e Feitosa, 2014.

Tais transformações comprometem o cenário paisagístico da Lagoa do Bacuri refletindo diretamente na beleza cênica do local, uma das forças motrizes para o desenvolvimento do turismo na região. Assim como podem vir a comprometer a qualidade ambiental da Lagoa, impossibilitando a realização de algumas atividades, como banho e outros.

É necessário que haja investimento e colaboração entre os órgãos governamentais e a comunidade local para que desta maneira, o processo de elaboração de planos para desenvolver a atividade turística na área possam contemplar a sustentabilidade ambiental, social e econômica. Pautando-se em atividades como o turismo que possibilita através da conservação ambiental a geração de renda para algumas coletividades.

É importante destacar a necessidade de se trabalhar a capacitação e a sensibilização da comunidade para o turismo como atividade que possa contribuir com a renda em escala local e a importância de conservar a Lagoa do Bacuri não somente pelo fato de sua beleza cênica, mas também pela importância deste sistema ambiental para o Baixo Parnaíba e para própria subsistência das comunidades do seu entorno.

\section{CONSIDERAÇÕES FINAIS}

A lagoa do Bacuri possui potencial natural necessário para desenvolver segmentos do turismo ecoturismo, turismo rural, turismo de aventura e etc.. Porém, é necessário que haja um interesse mútuo por parte do poder público, das populações da região e da iniciativa privada para o desenvolvimento do turismo local. 
Para que seja pensado uma proposta de turismo relacionada às condições atuais da área é de suma importância que sejam traçadas estratégias por parte das comunidades da área e do poder público para o desenvolvimento do turismo na região que seja fundamentada em um planejamento sustentável das potencialidades naturais da região para o turismo (RIBEIRO, 2015).

O pouco incentivo dos órgãos competentes e a não efetivação das políticas públicas voltadas para o melhoramento da infraestrutura local e para o incentivo do turismo dificulta a geração de renda e a oportunidade de emprego, posto que o incentivo destas práticas na área ainda é incipiente. E as poucas iniciativas que tiveram, foram externas, advindas de iniciativas de instituições de ensino superior junto a algumas comunidades da área.

A lagoa do Bacuri proporciona as comunidades que vivem as suas margens o potencial para o desenvolvimento de atividades turísticas. Porém, é notável a falta de estrutura, tanto para suprir necessidades básicas das comunidades quanto para receber visitantes, como: pousadas, água potável e encanada, saneamento básico, estruturas adequadas para alimentação como restaurantes e lanchonetes e principalmente a falta de pessoas capacitadas para o recebimento de turistas (RIBEIRO, 2015).

Além do investimento na infraestrutura da área para o desenvolvimento de um turismo sustentável, é primordial dá ênfase ao conhecimento das potencialidades e fragilidades ambientais da área, visto que o conhecimento das características naturais e de seus processos é essencial tanto para a conservação do ambiente e garantia do desenvolvimento do turismo na região, como para valorização das estruturas existentes nas comunidades nativas, visando além da geração de empregos para a comunidade, a melhoria na qualidade de vida da população da área.

\section{REFERÊNCIAS}

BOAS, G. H. V; MARÇAL, M. S. Geologia e estudo da paisagem aplicados ao turismo. In Geografia Aplicada ao Turismo. 1 ed. São Paulo: Oficina de textos, 2014. 191p.

FEITOSA, A.C. A Sustentabilidade na relação homem-ambiente na área maranhense do Delta do rio Parnaíba. Relatório Técnico apresentado a Fundação de Amparo a Pesquisa, Ciência e Tecnologia do Estado do Maranhão. FAPEMA. 2015. 49p.

MINISTÉRIO DO MEIO AMBIENTE. Zoneamento da Região do Baixo Parnaíba - 2002. Disponível em: www.mma.com.br. Acesso em: 04/08/2016. 81p.

MONTEIRO, C. Geossistemas: a história de uma procura. São Paulo: Contexto, 2001. 128p.

OMT (Organização Mundial do Turismo). Turismo internacional: uma perspectiva global. 2. ed. São Paulo: Bookman, 2003. 254p. 
RABELO, T. O. O Índice de Vulnerabilidade Ambiental (IVA) como instrumento para o planejamento ambiental da lagoa do bacuri - MA. Trabalho de conclusão de curso apresentada ao Curso de Geografia Licenciatura e Bacharelado da Universidade Federal do Maranhão. São Luís, 2015. $61 \mathrm{p}$.

RABELO, T. O; FEITOSA. A. C. A relação homem - ambiente na área maranhense do Delta do rio Parnaíba: a sustentabilidade dos recursos hídricos na Lagoa do Bacuri. Relatório Final entregue à Fundação de Amparo à Pesquisa e ao Desenvolvimento Científico e Tecnológico do Maranhão, 2014. 40 p.

RABELO, T.O. O Índice de Vulnerabilidade Ambiental (IVA) como instrumento para o planejamento ambiental da Lagoa do Bacuri - MA. Monografia presentada ao curso de geografia da Universidade Federal para obtenção de grau de bacharel e licenciatura em Geografia. UFMA. 2015. 62p.

RIBEIRO, N.R. Percepção ambiental e turismo sustentável: o turismo de base comunitária no povoado do Bacuri, Magalhães de Almeida -Maranhão. Monografia presentada ao curso de geografia da Universidade Federal para obtenção de grau de bacharel em Geografia. UFMA. 2015. $54 \mathrm{p}$.

SANTOS, N.M. Dinâmica da Paisagem: o uso do índice de vegetação para indicar alterações na cobertura vegetal na área de entorno da lagoa do Bacuri - MA. Monografia presentada ao curso de geografia da Universidade Federal para obtenção de grau de bacharel em Geografia. UFMA. 2015. 64p.

SANTOS, N.M.; NETO, O.M.; SOUZA, U.D.V. e FEITOSA, A.C. Turismo Sustentável no povoado do Bacuri, Magalhães de Almeida, Ma. Anais do V Simpósio Nacional de Turismo Sertanejo. João Pessoa, Paraíba. UFPB. 2014. 11p.

SEABRA, G. Turismo Sertanejo. João Pessoa: Editora Universitária, UFPB. 2007. 174p.

XAVIER, H. A percepção geográfica do turismo. São Paulo: Aleph, 2007. 106p.

Recebido em: 14/08/2016

Aceito para publicação em: 01/10/2016 